\title{
A mudança linguística no emprego do artigo no português
}

Simone Floripi*

\begin{abstract}
RESUMO: Este trabalho trata da mudança que ocorreu nos padrões de aplicação do determinante em sintagmas nominais possessivos do Português Brasileiro (PB) nos séculos 18 e 19 e do Português Clássico (PC) do século 16 ao século 19. Conforme estudos anteriores (cf. Floripi 2008, 2014), verificamos que o emprego do artigo em períodos anteriores do Português Europeu (PE) era reduzido, mas sofreu um paulatino aumento ao longo dos séculos até sua obrigatoriedade atual em contextos específicos. Faremos uma investigação diacrônica em relação ao emprego do artigo por meio de dados da língua portuguesa. Abordaremos o estudo de Kabatek (2007) a respeito do artigo nas línguas românicas no intuito de trazer para discussão seus dados sobre um possível panorama de mudança e corroborá-los a partir dos resultados obtidos na presente pesquisa.
\end{abstract}

PALAVRAS-CHAVE: Mudança linguística. Artigo. Sintagma possessivo. Português europeu. Português brasileiro.

\begin{abstract}
This paper presents the linguistic change on the application of article on possessive phrases from $18^{\text {th }}$ to $19^{\text {th }}$ centuries of Brazilian Portuguese and from $16^{\text {th }}$ to $19^{\text {th }}$ of Classical Portuguese. Some investigations (cf. Eloripi 2008, 2014) attest that the use of the article in ancient times of European Portuguese was low, increasing this number during centuries until your total use on specifics contexts. We will investigate the article use on Portuguese through a diachronic approach. We consider the grammaticalization process that occurred in Romanic languages discussed in Kabatek (2007) in order to discuss and corroborate his hypothesis using our data obtained on the present research.
\end{abstract}

KEYWORDS: Linguistic change. Article. Possessive phrase. European Portuguese. Brazilian Portuguese.

\section{Introdução}

Kabatek (2007) aborda a mudança linguística que ocorreu no emprego do artigo nas línguas românicas sob a perspectiva do processo de gramaticalização. Em sua investigação é feita uma comparação entre algumas línguas românicas, tais como o francês, italiano, espanhol e português para demonstrar os padrões de estrutura sintática característicos de cada uma delas a respeito da aplicação do artigo. E ao tratar da língua portuguesa, em específico, percebe que o português europeu apresenta um comportamento diferente do português brasileiro quanto ao uso do artigo, indo ao encontro de várias pesquisas feitas a este respeito que se utiliza de uma

\footnotetext{
* Doutora em Linguística pela Universidade Estadual de Campinas - UNICAMP e professora do Instituto de Letras e Linguística da Universidade Federal de Uberlândia - UFU.
} 
abordagem teórica distinta (cf. CASTRO (2000, 2006), FLORIPI (2008, 2014), SILVA (1996), SCHOORLEMMER (1998), e MAGALHÃES (2002)), mas que não invalidam, de modo algum, os resultados encontrados. Dessa maneira, adotamos a discussão a respeito do emprego do artigo em Kabatek (2007), no intuito de apresentarmos resultados quantitativos acerca do português europeu e do português brasileiro, de forma a embasar as considerações do autor.

Para a presente pesquisa, utilizamos como corpus de análise, dados do português brasileiro $(\mathrm{PB})$ e do português clássico $(\mathrm{PC})$. No que concerne ao $\mathrm{PB}$, selecionamos três materiais distintos elaborados no âmbito do "Projeto Para a História do Português Brasileiro" (PHPB), são eles: Cartas de Aldeamento de Índios do Arquivo Histórico do Estado de São Paulo (AHESP), datadas do século 18, Cartas Paulistas da Biblioteca Nacional do Rio de Janeiro, datadas do século 18 e edição da Correspondência Passiva de Washington Luiz, datada do século 19. Com relação ao português europeu ou português clássico, apresentaremos resultados retirados de Floripi (2008), pesquisa que investigou a estrutura de sintagmas nominais possessivos de vinte e três textos de autores portugueses, constituintes do Corpus Anotado do Português Histórico Tycho Brahe ${ }^{1}$.

\section{A mudança no emprego do artigo nas línguas românicas}

Roberts e Roussou (2003, p. 2) fazem uma análise geral sobre um fenômeno diacrônico, a gramaticalização. De acordo com tal proposta, os processos de mudança que ocorrem nas línguas são decorrentes da aplicação de um mecanismo natural, a partir da simplificação nas escolhas das estruturas sintáticas, gerando um processo de gramaticalização, i.e., um tipo de propagação natural de mudança a partir de estruturas lexicais, passando a estruturas mais gramaticais (ou funcionais) ao longo do tempo.

A gramaticalização é um processo comum que representa uma forma natural de mudança endógena, ao seguir um padrão na mudança linguística, expresso como uma tendência para a mudança. A gramaticalização envolve a criação de novo material funcional decorrente da reanálise dos materiais funcionais existentes ou por meio da reanálise de material lexical. Este fenômeno frequente nas línguas pode ser visto como o resultado de uma reanálise que afeta uma subclasse de itens lexicais sempre envolvendo simplificação estrutural.

\footnotetext{
${ }^{1}$ Os textos do corpus Thyco Brahe estão disponibilizados no site: www.ime.usp.br/ tycho/corpus.
} 
O termo gramaticalização do inglês grammaticalization (cf. HOPPER; TRAUGOTT, 1993) é usado de maneira não uniforme, com diferentes restrições. Esta definição pode implicar em uma graduação do termo gramática em um continuum ${ }^{2}$. Também se considera que a "Gramaticalização consiste no aumento do domínio de um morfema, avançando de um status lexical para um status gramatical, ou de um menos gramatical para um mais gramatical, por exemplo, de um formante derivacional a um flexional” (KURYLOWICZ, 1965, p. 69). Na literatura da área, este termo é empregado em analogia à lexicalização para todos os processos nos quais um elemento qualquer se integra ao sistema gramatical de uma língua.

Conforme apresentado por Kabatek (2007), no que concerne à mudança linguística no emprego do artigo, Greenberg $(1978,1991)$, ao estudar várias línguas da família Níger-Congo, propõe uma escala de sua evolução. Essa escala constitui-se de quatro níveis com uma gradação das especificações e contextos em que o artigo pode ser empregado nas línguas, elencados abaixo:

- No nível zero - encontram-se os demonstrativos. Esta é a origem mais comum do artigo definido, como por exemplo, ocorreu nas línguas derivadas do latim.

- No nível um - o demonstrativo, depois de redução da sua força dêitica, torna-se um identificador para aqueles elementos conhecidos através do contexto ou devido ao seu caráter universal, como por exemplo, o sol.

- $\quad$ No nível dois - o uso do artigo aumenta, podendo ser utilizado junto a quase todos os tipos de substantivos. Nesse nível, a colocação de um artigo passa a apresentar uma redundância, principalmente junto a nomes próprios, predicados nominais e objetos negados.

- Já no nível três, último nível da escala de Greenberg, o artigo é ampliado a todos os substantivos. Quando isso ocorre não se percebe uma diferenciação de sentido com ou sem artigo. Nesse estágio, não há mais função denominativa do artigo, passando apenas a um marcador nominal. Mesmo nos casos em que o artigo tinha funções secundárias, como marcar gênero ou número, essas também se tornam funções principais, junto com a marca nominal, assim como o artigo serve para a substantivação de elementos verbais.

\footnotetext{
${ }^{2}$ Como princípios básicos do processo de gramaticalização empregam-se as noções de: i) unidirecionalidade, ii) irreversibilidade de processos de gramaticalização e iii) Princípio da ciclicidade.
} 
Kabatek (2007) ao comparar algumas línguas românicas para verificar a mudança histórica do artigo, remete à obrigatoriedade do seu emprego, comum às línguas românicas. Para o autor, é possível verificar um processo de gramaticalização nessas línguas, que foi estabelecido por meio de um ciclo de ocorrências, conforme proposto por Greenberg (1978). Para Kabatek (2007, p. 17) a escala de Greenberg revela uma correlação entre a evolução do ciclo com a impossibilidade de se utilizar um substantivo sem artigo. Ou seja, ao passo que o ciclo evolui, o emprego do artigo tende a aumentar e as diferenciações entre casos com ou sem artigo não são mais percebidas, o que causa uma generalização de seu uso, empregando-o em quase todos os contextos.

No intuito de investigar em que nível o francês, espanhol, português brasileiro e português europeu são enquadrados na escala de Greenberg, Kabatek (2007) apresenta um panorama geral de ocorrências do artigo nessas línguas. Vejamos alguns exemplos retirados de Kabatek (2007, p. 19-20) a respeito do francês, pois esta é a língua que mais se enquadra à escala de Greenberg, ocupando uma posição mais avançada dos níveis em relação às demais línguas latinas.

No caso do francês, em que o uso do artigo é comum nas estruturas, ainda é possível encontrar vários contextos em que o mesmo não é realizado, conforme os exemplos a seguir:

(1)a. Il est avocat.

b. avec courage/avec un courage fou/ avec le courage que 1'on sait/avec du courage, on arrive à tout.

c. Pierre parle trop.

d. Avoir soif, avoir faim, avoir peur, perdre patience, rendre justice etc.

e. Sonia Iglésias, chercheuse au Musée dês cultures populaires...

$\mathrm{f}$. Mais dès le Championnat termine, je remettrai casque et épaulières.

g1. Livres, cahier et stylos tombèrent.

g2. Des livres, des cahiers et des stylos tombèrent.

g3. Les livres, les cahiers et les stylos tombèrent.

Dadas algumas condições ainda é possível a não realização do artigo no francês, em (1a) a "condição especial" é a função atributiva, em (1b) o uso de sintagmas preposicionados, em (1c) nomes próprios, em (1d) locuções verbais, em (1f) e (1g) por estarem em construções coordenadas

De acordo com Kabatek (2007), pelo comportamento do francês moderno, são poucos os casos em que o substantivo ainda aparece sem artigo, mas ainda é mantida uma oposição 
com relação ao seu uso. O autor aponta também casos de fraseologismos ${ }^{3}$ onde o artigo pode não ser usado (cf. Kabatek 2007 p. 20-21), conforme notamos a seguir.

(2)a. Pierre qui roule n'amasse point mousse.

b. Biére qui mousse n'a plus de goût.

c. La/une pierre qui roule n'amasse pas de mousse.

d. ? Vache qui rit ne mange pas de foin.

Da mesma forma, no português europeu podem ser encontrados fraseologismos com "nomes nus"4 (ou Bare Nouns), no início da frase.

(3)a. Cão que ladra nunca é bom para a caça.

b. Pobreza não é vileza.

c. Em boca fechada não entra mosca.

Assim como o português europeu, no português brasileiro são encontrados fraseologismos com "nomes nus", conforme elencado abaixo.

(4) a. Santo de casa não faz milagre.

b. Sertanejo não sabe chorar.

c. Menino incomoda.

Além desses casos, Kabatek (2007) percebe que o uso genérico da palavra sem o artigo não é restrito apenas aos fraseologismos ou aos provérbios. Esse tipo de construção tem sido bastante frequente nas áreas de marketing e propaganda para criar um efeito estilístico.

(5) a. Bicicleta não polui. /Crianças começam a fumar ao verem os adultos fumando (painéis do Rio de Janeiro).

b. Liberdade não vem de graça. Mas pode vir em 10 vezes sem juros (publicidade na internet da Mercedes Bens do Brasil).

c. Eu acho que filho dá trabalho desde a hora que nasce.

\footnotetext{
3 Fraseologismos são estudados pela lexicologia. Apenas a título de informação, segue a definição de fraseologismo, segundo Klare (1986, p. 355) "Enquanto as palavras normalmente são constituídas de um único corpo, os fraseologismos compõem-se de vários formativos que formalmente podem ser considerados como palavras".

${ }^{4}$ Um nome nu é um substantivo que não denota entidades massivas (por exemplo: arroz e água) e que aparece sem a precedência de um quantificador (um artigo ou um numeral) na sentença.
} 
Há omissão do artigo na linguagem jornalística com artigos definidos e indefinidos, conforme exemplificado abaixo.

(6) a. Artigo defendendo essa tese foi recentemente publicado no... (Folha de S. Paulo, 19/09/2000)

b. Raridade mesmo são quatro outras faixas (Jornal do Brasil, 19/09/2000).

c. Site oficial, a candidatura já tem (Folha de S. Paulo, 17/12/2000).

Como vemos, os jornalistas usam substantivos sem artigos como um recurso estilístico capaz de permitir que o caráter de imediação do substantivo seja destocado para o primeiro plano $^{5}$. Além dos contextos de linguagem jornalística e textos escritos, o artigo também pode ser omitido em textos do registro oral, distantes da norma culta, conforme percebemos nos exemplos de Kabatek (2007).

(7) a. Bicicleta ia se arrebentar.

b. A gente queria agora gravação de pessoas conversando.

c. Diminuiu turista aqui.

Conforme evidenciado pelos exemplos acima, há vários contextos em que o artigo não tem sido empregado na língua portuguesa. Para Kabatek (2007), se há um padrão de aplicação do uso do artigo na língua falada e também na língua escrita, uma vez que esta é mais conservadora, tal padrão deveria ser uma evidência da propagação de uma mudança linguística, mas o autor apresenta ressalvas.

Notamos que a omissão do artigo aplica-se em contextos escritos e também na fala não standard. Poderíamos pensar que estes são indícios de haver uma difusão da omissão do artigo na língua, entretanto, o fato de não haver artigo em alguns contextos definidos não é suficiente para tal afirmação. Para tanto seria necessária uma coleta de dados para verificação de tal hipótese.

Percebemos que o uso do substantivo sem artigo no PB é abrangente, diferenciando-se de outras línguas. Nesse ponto, o PB apresenta um caráter mais arcaico do que o PE e o espanhol atual o que se aproximaria das línguas românicas da época medieval. Entretanto, nos exemplos

\footnotetext{
${ }^{5}$ Há situações cânones em que não se usa artigo, independentemente do contexto situacional, por exemplo: Em i) provérbios - "tempo é dinheiro", em ii) definições - "política é a arte do possível", em iii) vocativos, em iv) expressões fixas - "declarar guerra, dar esmola", etc. v) Depois de cujo, vi) antes de superlativo e nas associações de determinados verbos e substantivos - "pedimos permissão; Não tive tempo para sair".
} 
acima apresentados, há substantivos em contextos claros de determinação, mas que não aparecem antecedidos pelo artigo. E estes são contextos em que se empregava o artigo nas demais línguas românicas desde a Idade Média. Dessa maneira, tal particularidade encontrada no PB não pode ser considerada arcaísmo, uma vez que o português antigo já tinha gramaticalizado o uso do artigo. Portanto, para Kabatek (2007, p. 40), casos em que há um contexto claro de determinação, mas não empregam o artigo podem ser considerados como inovação do PB uma vez que tal contexto leva à obrigatoriedade do seu uso. E o mais surpreendente é que os resultados são contrários ao que se espera ocorrer nos processos de gramaticalização, pois não se verifica uma unidirecionalidade no processo de aplícação do artigo, como nas demais línguas românicas. Tal comportamento do PB, que pode ser considerado uma inovação, é diferente do que ocorre com o francês, por exemplo. Nesse caso, parece que o PB trilha um caminho próprio, novo na tipologia das línguas românicas.

Dessa forma, o estudo de Kabatek (2007) demonstra não haver uma unidirecionalidade no processo de gramaticalização do artigo no PB. O autor conchui que esta língua revela um comportamento único e distingue-se das demais línguas românicas. E ao tomarmos como base tais considerações do autor, buscamos atestar tal hipótese por meio de dados do emprego do artigo na língua portuguesa. Passemos, então, aos resultados obtidos na presente pesquisa.

\section{O uso dos artigos nos sintagmas possessivos na língua portuguesa: padrões e resultados}

Ao acolher a análise de Kabatek (2007), apresentaremos a seguir dados que corroboram tal proposta a partir de outro panorama de investigação sobre os sintagmas possessivos na língua portuguesa. Descreveremos a estrutura do sintagma com base na Teoria de Princípios e Parâmetros (cf. CHOMSKY, 1995) para a descrição da estrutura gramatical investigada em que são determinadas ás posições ocupadas pelo artigo, substantivos e pronome possessivo no português europeu e brasileiro a fim de descrevermos os padrões de aplicação do artigo.

Como contexto de investigação desta pesquisa, optamos por considerar apenas o emprego do artigo junto aos sintagmas nominais possessivos. Este contexto, já amplamente investigado em pesquisas anteriores (cf. SILVA (1982), MAGALHÃES (2002), CASTRO (2006) e FLORIPI (2008)) demonstra ser capaz de mapear este processo de mudança sintática na língua portuguesa. 


\subsection{Estrutura do sintagma nominal possessivo}

Trataremos mais especificamente do emprego do artigo em sintagmas nominais possessivos pré-nominais no português, como exemplificado abaixo.

(8)a. O meu livro novo chegou

Português clássico / português brasileiro.

b. Meu livro novo chegou

c. O meu livro novo chegou

d. * Meu livro novo chegou

Português europeu moderno.

Em diversas línguas, afirma-se que os pronomes possessivos estão localizados dentro do sintagma nominal (DP), em posição de núcleo de determinante (D) ou em especificador (Spec, DP) (cf. OLSEN (1989), DEMSKYE (1995), entre outros). Tal posição comprova que em certas línguas como inglês, holandês e francês o possessivo não coocorre com o determinante, conforme apresentado nos exemplos a seguir.

(9)a. (*The) my book

b. (*Het) mijn boek

c. $\left({ }^{*}\right.$ Le) mon livre

d. O meu livro

'o meu livro'
Inglês

Holandês

Francês

Português

Contudo, como notamos em (9d) há línguas, como o português, em que é possível esta ocorrência. A explicação para tal fenômeno é que os possessivos não são equivalentes a determinantes definidos mesmo quando eles parecem ocupar a posição de um determinante; Este fato nos indica haver posições específicas na estrutura do sintagma nominal, uma para o determinante e outra diferente para o possessivo. Outro caso, apresentado em (10) abaixo, trata da co-ocorrência de um artigo e um possessivo em elipse de um sintagma determinante.

Conforme observado em (10), em algumas línguas há diferentes formas para o possessivo, a depender de sua posição na estrutura, dada a necessidade da concordância da morfologia do possuidor.
(10)a. my book
a'. Your book, not mine
Inglês.
b. mon livre
b'. Ton livre à toi, pas le mien
Francês.
c. mein Buck
$\mathrm{c}^{\prime}$. Dein Buch, nicht meins / das meinige Alemão. 'meu livro' 'seu livro, não meu'. 
Os exemplos acima também nos sugerem haver posições específicas para a realização de cada tipo de possessivo, a depender de sua posição no DP. Dessa maneira, para indicarmos o posicionamento de cada um dos elementos tratados (determinante e possessivo) consideramos a estrutura interna do DP que pode ser comparada à estrutura de uma sentença $(\mathrm{CP})$, pois, do mesmo modo que ocorre nos CPs, o elemento possuidor carrega certos traços que precisam ser checados fora do constituinte onde ele foi gerado como possuidor. Isso requer a existência de projeções funcionais dentro do DP para que os traços de Concordância e Caso possam ser checados.

Vejamos a seguir dados do português contemporâneo, utilizando a estrutura do DP proposta por Shoorlehmer (1998) e Szabolcsi (1994), entre outros.

os meus dois cadernos

DP
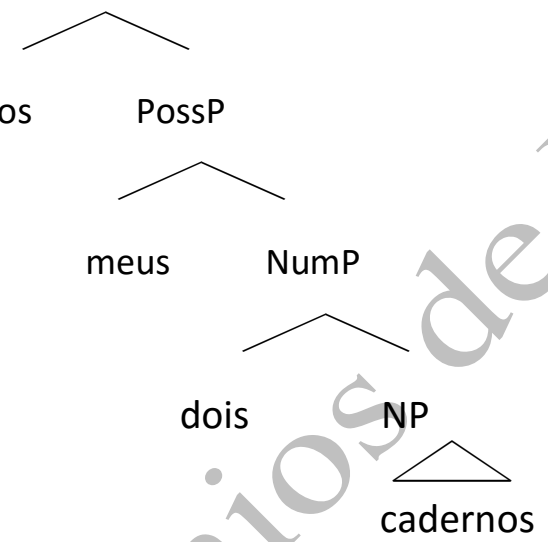

Os pronomes possessivos, por exemplo, podem ser inseridos em posição de núcleo, como Poss ${ }^{0}$. Essa arquitetura captura para o português, a instanciação do pronome possessivo entre D e Num e é em seus domínios de checagem que um dado constituinte vai ser interpretado como o possuidor de $\mathrm{N}$.

Shoorlemmer (1998) leva em consideração um conjunto de diferenças entre línguas que apresentam a propriedade de checar o traço mais definido de construções possessivas em oposição a línguas que não operam desta forma, evidenciando o licenciamento de estruturas em que há a co-ocorrência de pronomes e artigos.

Passemos aos resultados obtidos por meio da busca, classificação e quantificação dos dados de sintagmas possessivos em relação à aplicação do artigo na língua portuguesa, no decorrer dos séculos. Primeiramente apresentaremos alguns resultados do português clássico, 
obtidos em Floripi (2008). Em seguida, apresentaremos os dados do português brasileiro dos séculos 18 e 19, recolhidos pela presente pesquisa no intuito de mapearmos o perfil sintático da língua portuguesa e evidenciarmos, por meio de dados quantitativos, a hipótese de Kabatek (2007).

\subsection{Padrões de aplicação do artigo nos DPs possessivos do português clássico}

Para a escolha dos contextos a serem investigados, esta pesquisa baseou-se no trabalho de Silva (1982) e Magalhães (2002) sobre o uso de artigo frente a possessivos no português europeu e no português brasileiro. A busca dos contextos estudados resultou em dez tipos de contextos que dependiam:

(i) da presença ou ausência do artigo,

(ii) da sua posição na oração e

(ii) da presença ou ausência da preposição.

Atendemos os contextos acima para a seleção dos dados e constatamos uma relação bastante intrincada entre a presença ou ausência do artigo com a realização de uma preposição.

$\mathrm{Na}$ atualidade o português europeu exige o emprego obrigatório do artigo junto a DPs possessivos, mas esta exigência da gramática da língua deve-se a uma mudança ao longo de séculos de existência, pois em tempos passados não havia tal obrigatoriedade.

O gráfico abaixo, retirado de Floripi (2008), evidencia a mudança sintática que ocorreu no português clássico em relação ao crescimento no número de ocorrências de artigos ${ }^{6}$.

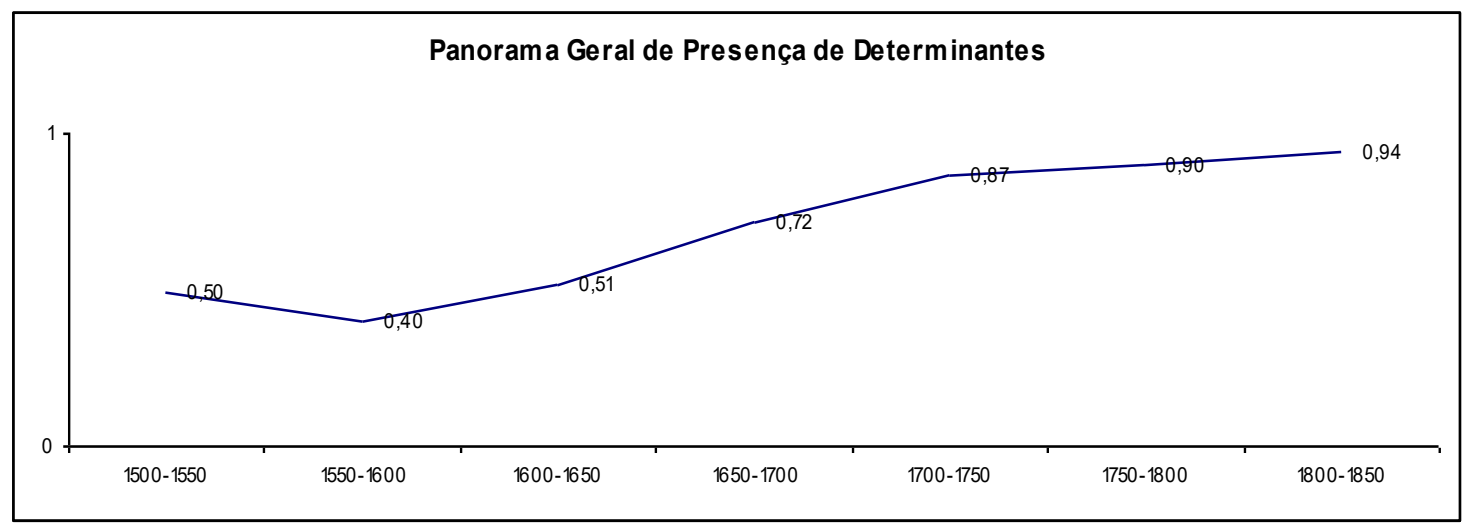

Gráfico 1. Percentual de ocorrências do determinante nos DPs possessivos no português clássico.

\footnotetext{
${ }^{6} \mathrm{O}$ quadro apresenta os resultados acerca do emprego do artigo em sintagmas possessivos obtidos em 23 textos de autores portugueses no PC, conforme mencionado anteriormente. Os resultados foram agrupados a cada 50 anos para facilitar a visualização dos mesmos.
} 
A mudança ao longo do tempo revela que, a partir da segunda metade do século 17 , o uso do artigo diante do pronome possessivo passa a ter um crescimento acentuado, de $50 \%$ a $70 \%$, o que demonstra o início de uma mudança com relação à aplicação mais regular do determinante neste contexto ${ }^{7}$.

Segue o quadro geral com as quantificações de determinantes encontrados nos DPs possessivos nos 23 textos investigados do português clássico retirado de Floripi (2008, p.139) A partir dos dados apresentados a seguir foi elaborada a planilha apresentada no gráfico 1, acima.

Quadro 1. Número de ocorrências de determinantes em DPs possessivos no português clássico.

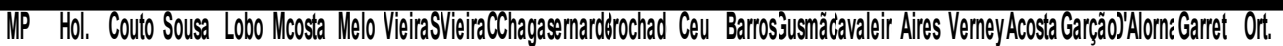
$\begin{array}{lllllllllllllllllllllll}1510 & 1517 & 1542 & 1556 & 1579 & 1601 & 1600 & 1608 & 1600 & 1631 & 1644 & 1651 & 1658 & 1675 & 1699 & 1702 & 1705 & 1713 & 1714 & 1724 & 1750 & 1799 & 1836\end{array}$

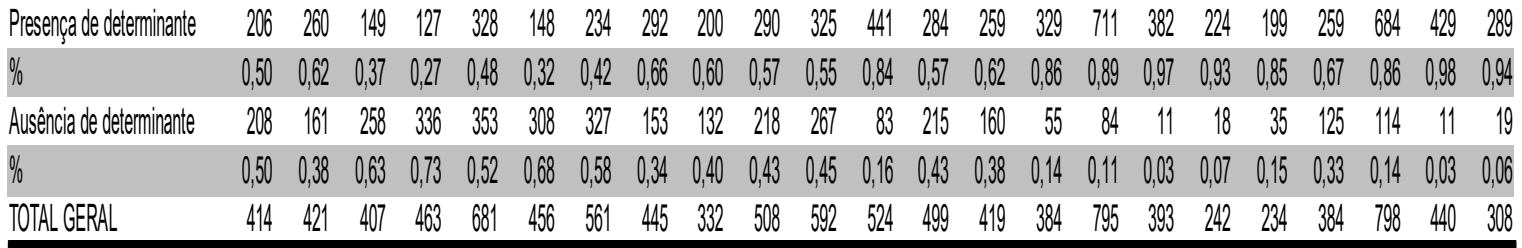

Averiguamos as ocorrências de presença e ausência de determinante nos sintagmas possessivos em todos os contextos sintáticos. Vale salientar que foi obtido um montante de cerca de 10.000 dados no total $^{9}$, a partir de 10 contextos estruturais elaborados com relação ao tipo de pronome possessivo, posição do DP na estrutura sintática, tipo de determinante e função sintática do DP. Dada à robustez dos resultados obtidos por Floripi (2008), temos maior segurança para identificar o comportamento da aplicação do determinante nos sintagmas possessivos ao longo dos séculos.

Apresentamos abaixo o quadro retirado de Floripi (2008) que apresenta o número de ocorrências de artigos de acordo com os contextos sintático dos DPs possessivos.

\footnotetext{
${ }^{7}$ Não há uma regra para determinar a mudança em termos percentuais, contudo as variações no emprego de um contexto não devem ter grandes distinções. Assim, seria o caso de afirmarmos que o uso do artigo em possessivos está em processo de mudança, pois o aumento nos valores percentuais em $20 \%$ neste caso já é mais robusto para dizer que um padrão de mudança está em curso.

${ }^{8}$ Cada coluna apresenta o nome do autor do texto e data além dos dados obtidos em relação ao uso do artigo nos sintagmas possessivos.

${ }^{9}$ Os dados foram quantificados utilizando-se do pacote estatístico GoldVarb 2001 uma vez que lidávamos com um montante alto de ocorrências e com vários fatores estruturais envolvidos.
} 
Quadro 2. Número de ocorrências de determinantes em DPs possessivos no PC - contextos sintáticos.

\begin{tabular}{|c|c|c|c|c|c|c|c|}
\hline $\begin{array}{l}\text { Presença de Det em Sujeito } \\
\% \\
\text { Ausência de Det em Sujeito } \\
\% \\
\text { Total }\end{array}$ & \begin{tabular}{r|}
$1500-1550$ \\
711 \\
0,81 \\
17 \\
0,19 \\
88 \\
\end{tabular} & $\begin{array}{r}1550-1600 \\
68 \\
0,88 \\
9 \\
0,12 \\
77\end{array}$ & \begin{tabular}{|r|}
$1600-1650$ \\
245 \\
0,82 \\
52 \\
0,18 \\
297 \\
\end{tabular} & $\begin{array}{r}1650-1700 \\
140 \\
0,88 \\
19 \\
0,12 \\
159\end{array}$ & $\begin{array}{r}1700-1750 \\
292 \\
0,95 \\
16 \\
0,05 \\
308 \\
\end{array}$ & $\begin{array}{r}1750-1800 \\
181 \\
0,89 \\
23 \\
0,11 \\
204 \\
\end{array}$ & $\begin{array}{r}1800-1850 \\
40 \\
1,00 \\
0 \\
0,00 \\
40\end{array}$ \\
\hline Presença de Det em Obj. Direto & 94 & 63 & 272 & 221 & 377 & 240 & 61 \\
\hline & $\mathbf{0 , 8 5}$ & 0,69 & 0,84 & 0,96 & 0,98 & 0,97 & 0,98 \\
\hline Ausência de Det em Obj. Direto & $\begin{array}{r}16 \\
015\end{array}$ & 28 & 50 & 10 & & & \\
\hline $\begin{array}{l}\% \\
\text { Total }\end{array}$ & $\begin{array}{r}0,15 \\
110\end{array}$ & $\begin{array}{r}0,31 \\
91\end{array}$ & $\begin{array}{r}0,16 \\
322\end{array}$ & $\begin{array}{r}0,04 \\
231\end{array}$ & $\begin{array}{r}0,02 \\
386\end{array}$ & $\begin{array}{r}0,03 \\
247\end{array}$ & $\begin{array}{r}0,02 \\
62\end{array}$ \\
\hline Presença de Det em Obj. Indireto & 49 & 41 & 131 & 139 & 125 & 92 & 13 \\
\hline & 0,52 & 0,37 & 0,41 & 0,71 & $\mathbf{0 , 8 1}$ & $\mathbf{0 , 8 1}$ & 1,00 \\
\hline $\begin{array}{l}\text { Ausência de Det em Obj. Indireto } \\
\%\end{array}$ & $\begin{array}{r}45 \\
0,48\end{array}$ & $\begin{array}{r}71 \\
03\end{array}$ & $\begin{array}{r}190 \\
059\end{array}$ & $\begin{array}{r}56 \\
29\end{array}$ & $\begin{array}{r}29 \\
019\end{array}$ & $\begin{array}{r}21 \\
019\end{array}$ & $\begin{array}{r}0 \\
0\end{array}$ \\
\hline $\begin{array}{l}\% \\
\text { Total }\end{array}$ & 94 & 112 & 321 & 195 & 154 & 113 & 13 \\
\hline Presença de Det em Adjunto & 282 & 283 & 842 & 813 & 980 & 600 & 175 \\
\hline & 0,44 & 0,33 & 0,43 & 0,66 & 0,82 & $\mathbf{0 , 8 9}$ & 0,91 \\
\hline Ausência de Det em Adjunto & 363 & 581 & 1113 & 428 & 219 & 74 & \\
\hline & 0,56 & 0,67 & 0,57 & 0,34 & 0,18 & 0,11 & 0,09 \\
\hline Total & 645 & 864 & 1955 & 1241 & 1199 & 674 & 193 \\
\hline
\end{tabular}

A seguir apresentamos os dados acima em formato de planilha e agrupados em períodos de 50 anos. Observamos um comportamento diferenciado no uso do artigo em DPs possessivos a depender do contexto sintático em que é realizado (posição de sujeito, objeto direto, objeto indireto e adjunto). Vejamos os dados nas planilhas:

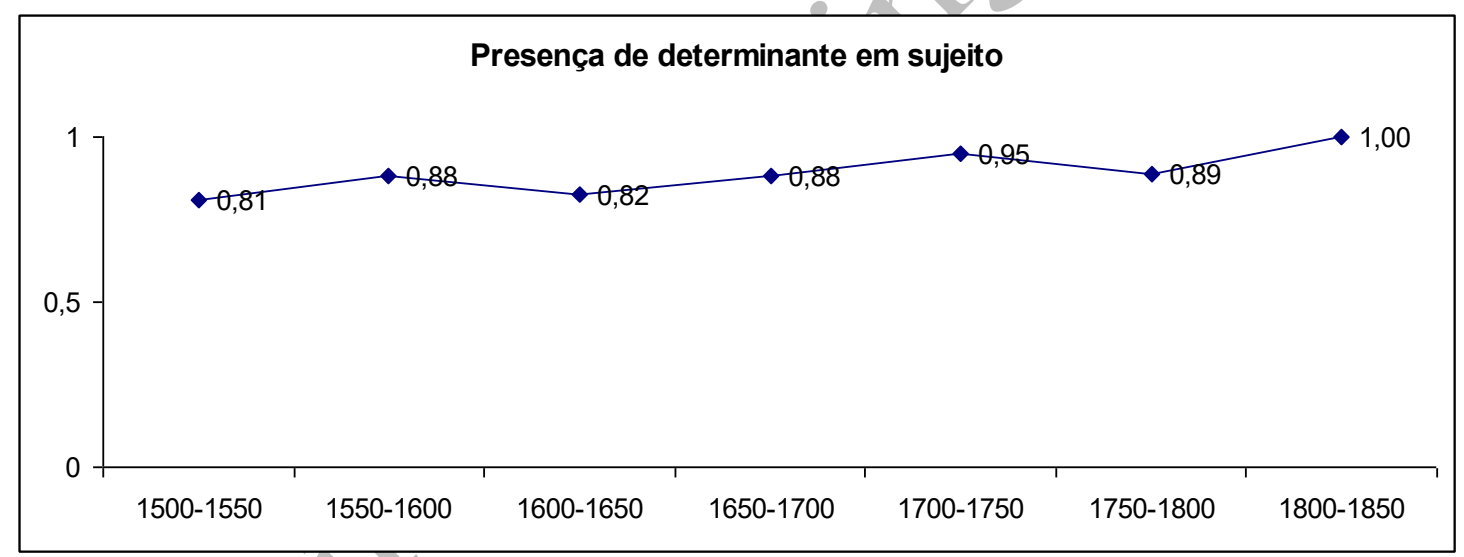

Gráfico 2. Percentagem do uso de determinantes em DPs possessivos (sujeitos) no português clássico.

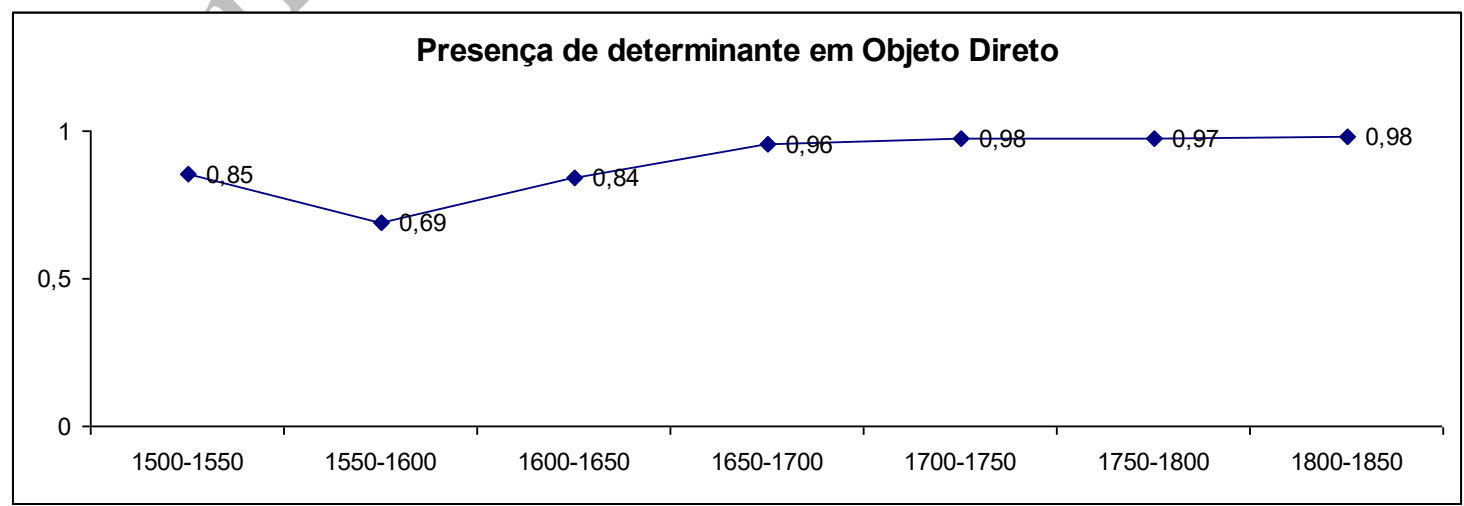

Gráfico 3. Percentagem do uso de determinantes em DPs possessivos (objetos diretos) no português clássico. 


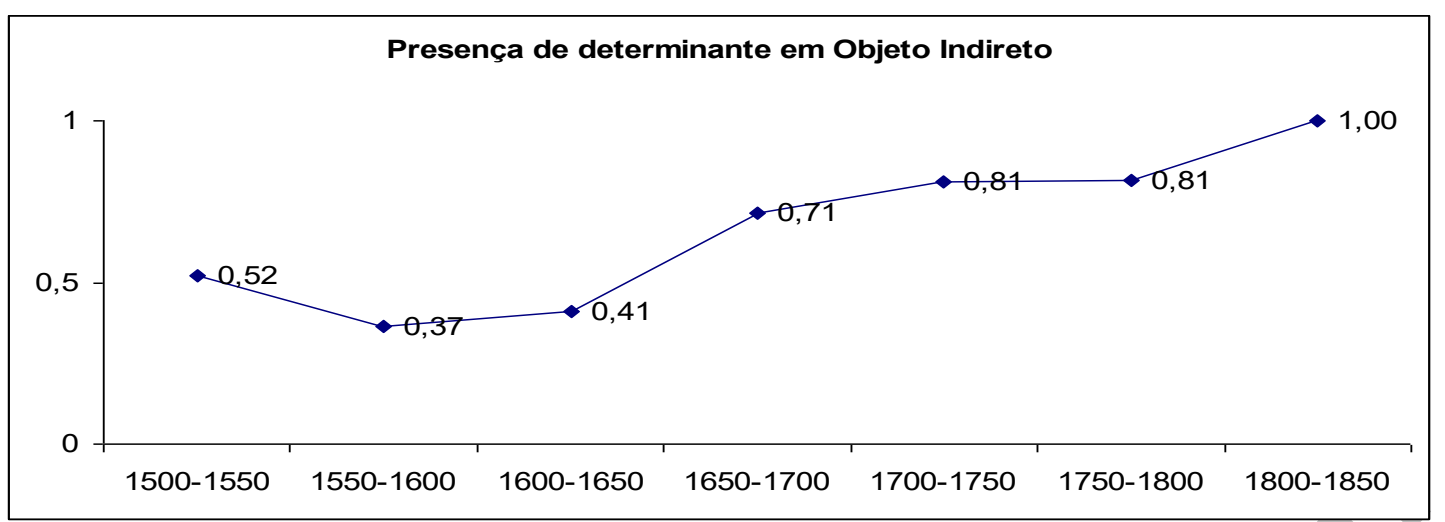

Gráfico 4. Percentagem do uso de determinantes em DPs possessivos (objetos indiretos) no português clássico.

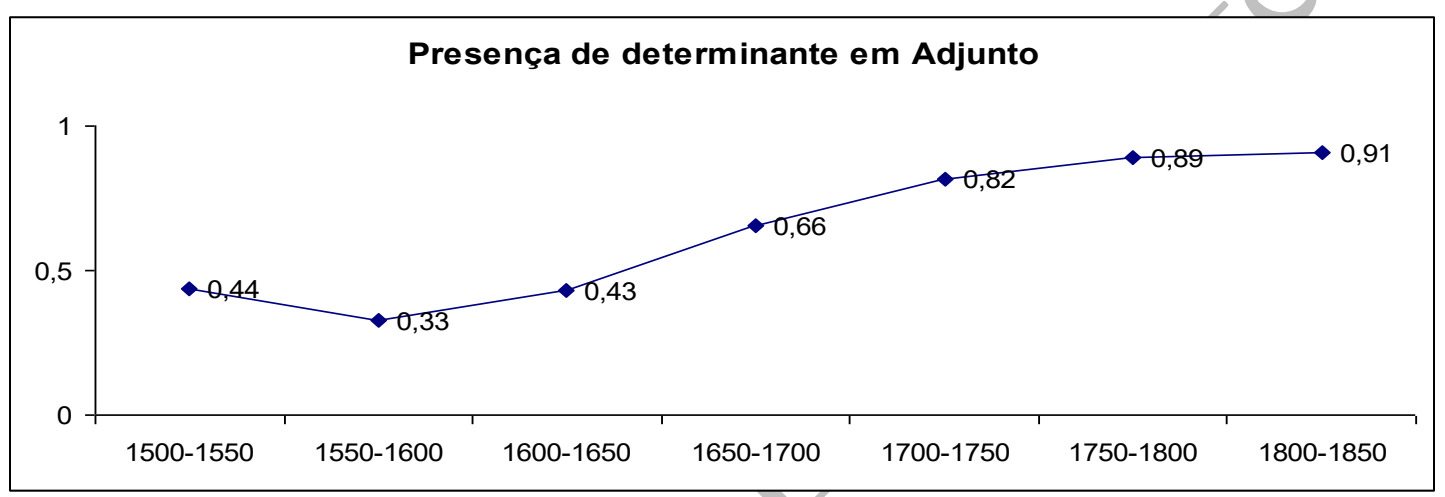

Gráfico 5. Percentagem do uso de determinantes em DPs possessivos (adjuntos) no português clássico.

De acordo com os dados do português clássico apresentados acima, é possível agrupar os casos de DPs sujeitos e objetos diretos de um lado e os objetos indiretos e os adjuntos, de outro. Com relação ao primeiro grupo, seu comportamento mostra casos em que o número de emprego de artigos era mais elevado desde o início do século 16 com uma pequena variação. Já para o segundo grupo, o número de ocorrências era mais baixo no início do século 16 havendo um posterior crescimento no decorrer dos séculos até uma quantidade elevada de uso do artigo no século 19. Essas diferenças não parecem ser aleatórias, pois justamente os contextos em que percebemos melhor a mudança na gramática do PC são aqueles em que se requer uma preposição, como nos objetos indiretos e nos adjuntos.

Como notamos, os resultados apresentados são capazes de mapear uma mudança linguística na língua portuguesa. Percebe-se que ao longo dos séculos o uso do artigo diante de sintagmas possessivos sofreu um aumento paulatino até culminar na sua obrigatoriedade nos dias atuais. Portanto, temos evidências da mudança ocorrida no português europeu. A partir destas informações, nos foi instigada a questão: Como seria o comportamento de tal estrutura 
sintática no português brasileiro? É possível determinarmos um panorama a respeito desta estrutura para o PB?

Com o intuito de responder a tais questionamentos buscamos realizar um mapeamento do uso do artigo em DPs possessivos no português brasileiro em textos de séculos passados. Vejamos os resultados nas próximas seções.

\subsection{Padrões de aplicação do artigo nos DPs possessivos do português brasileiro}

Para a obtenção dos dados do português brasileiro, utilizamos os mesmos procedimentos metodológicos de recolha, classificação e análise empregados em Floripi (2008). Trabalhamos com três conjuntos de material escrito, sendo este de número mais reduzido, se comparado com os dados de Floripi (2008). Entretanto os resultados evidenciam tendências semelhantes de aplicação do artigo em DPs possessivo, encontradas no português clássico. Vejamos o quadro abaixo com a quantificação dos dados.

Quadro 2. Uso de determinantes em DPs possessivos no português brasileiro.

\begin{tabular}{|c|c|c|c|}
\hline & $\begin{array}{l}\text { Cartas de } \\
\text { Aldeamento - } \\
\text { século } 18 \\
\end{array}$ & $\begin{array}{l}\text { Correspondência } \\
\text { Washington Luís } \\
\text { século } 19\end{array}$ & $\begin{array}{l}\text { Cartas } \\
\text { Paulista - } \\
\text { século } 19\end{array}$ \\
\hline $\begin{array}{l}\text { Presença de } \\
\text { determinante }\end{array}$ & 23 & 49 & 153 \\
\hline$\%$ & 0,37 & 0,27 & 0,72 \\
\hline $\begin{array}{l}\text { Ausência de } \\
\text { determinante }\end{array}$ & 39 & 132 & 59 \\
\hline$\%$ & 0,63 & 0,73 & 0,28 \\
\hline TOTAL GERAL & 62 & 181 & 212 \\
\hline
\end{tabular}

A partir/dos resultados apresentados no quadro acima, apresentamos o gráfico a seguir para melhor visualização das ocorrências. 


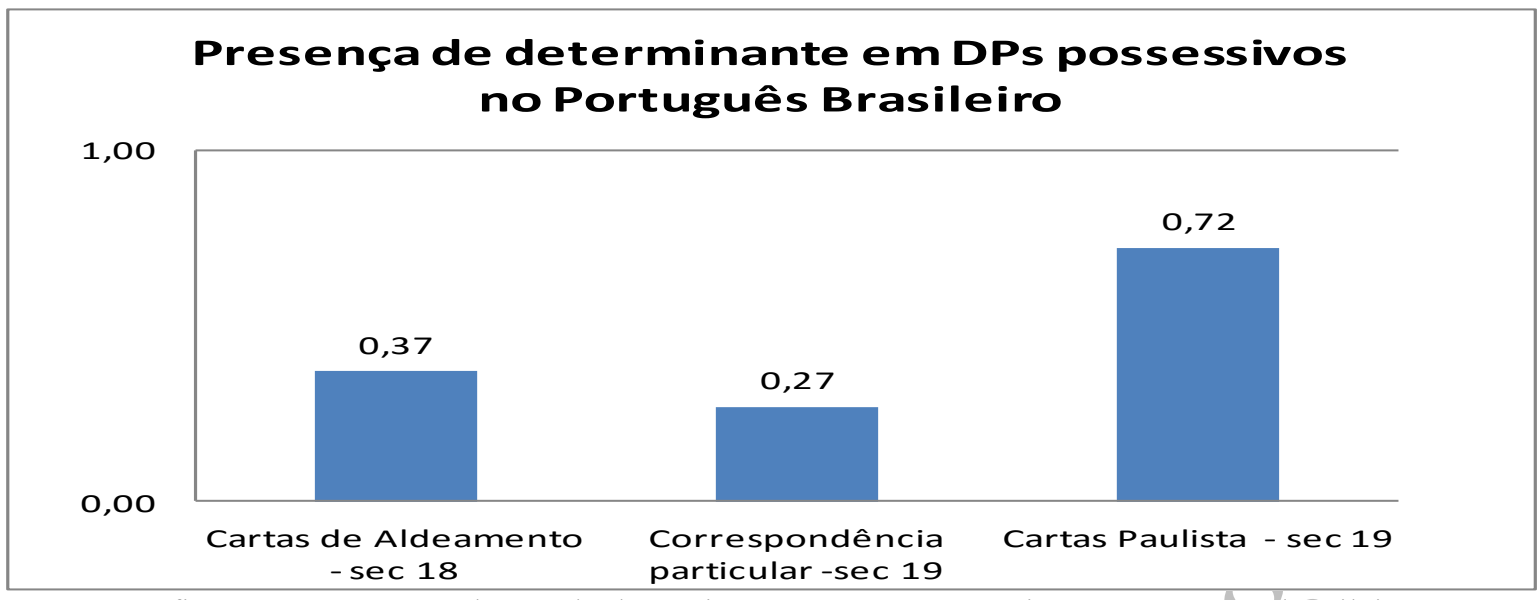

Gráfico 6. Percentagem do uso do determinante nos DPs possessivos no português brasileiro.

O quadro acima apresenta um panorama geral das aplicações de artigo no DP possessivo do PB. Ao analisarmos tais resultados, percebemos um aumento nos dados ao compararmos os resultados do século 18 com os do século $19^{10}$.

Dentro da pesquisa realizada, foram obtidas outras questões, mas diante da discussão proposta que, optamos por apresentar dados que nos chamam a atenção, os quais são aqueles em que há uma preposição envolvida. Dividimos os dados abaixo entre os que apresentam uma preposição frente ao DP possessivo e os que não apresentam tal preposição. Vejamos os resultados a seguir em planilhas distintas.

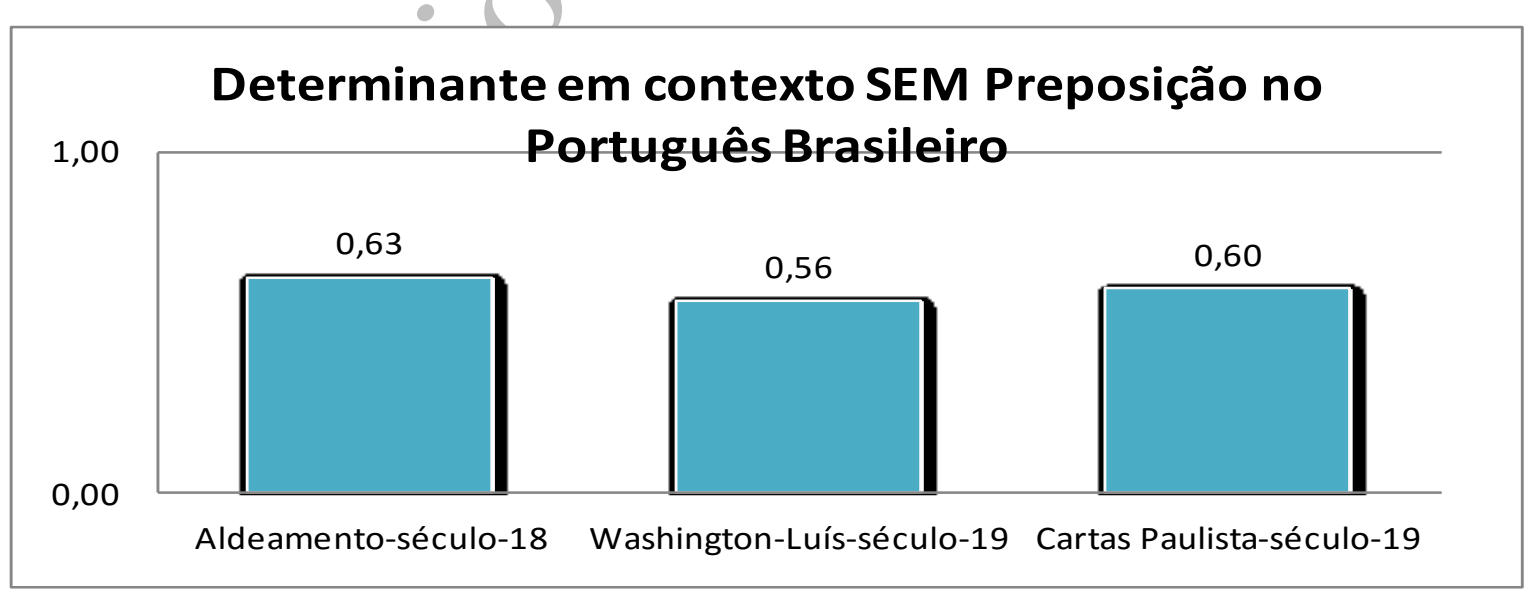

Gráfico 7. Percentagem do uso do determinante em DPs não preposicionados no português brasileiro.

\footnotetext{
${ }^{10} \mathrm{O}$ corpus da correspondência particular de Washington Luis apresenta dados que se distanciam do outro corpus do mesmo século. Ainda é necessário verificar mais a fundo o motivo de tal comportamento diferenciado.
} 


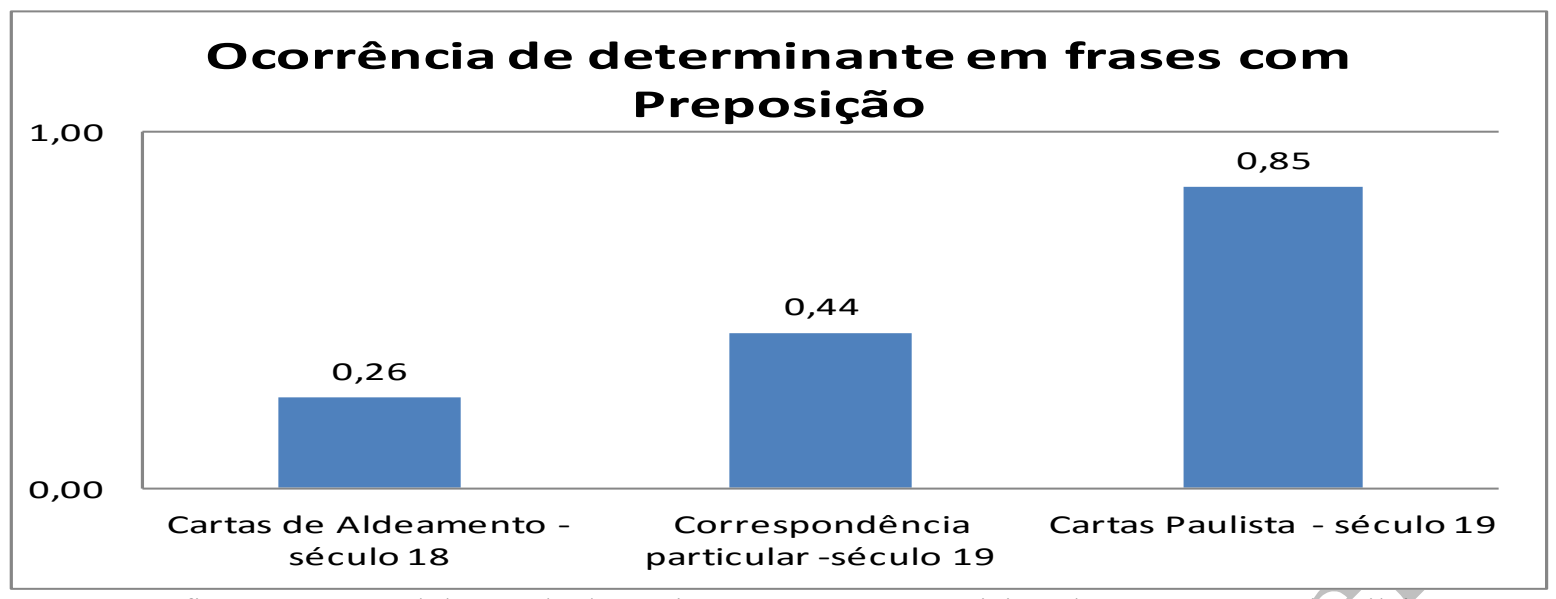

Gráfico 8. Percentual do uso do determinante em DPs preposicionados no português brasileiro.

Ao analisar os gráficos acima, verificamos que nos casos em que há uma preposição envolvida como no gráfico 8 , o número de ocorrências do artigo é menor, se comparado àqueles em que não há preposição no mesmo contexto.

Os resultados no gráfico 7 encontram-se no patamar de 50 a $60 \%$ de ocorrências no emprego do artigo, o que não é suficiente para dar indícíos que haveria uma mudança na sintaxe do português brasileiro. Já no gráfico 8 , quando há uma preposição, constatamos uma tendência para o aumento de ocorrências do artigo, passando de cerca de $30 \%$ para cerca de $80 \%$, o que revela um aumento considerável. Entretanto, ainda assim, não há evidências suficientemente robustas para afirmarmos que o PB está seguindo o mesmo caminho trilhado pelo PC clássico, em direção a um processo de emprego obrigatório do artigo nos pronomes possessivos, uma vez que os dados são restritos e também não são apresentadas ocorrências com $100 \%$ de realização, o que evidenciaria uma obrigatoriedade.

Kabatek (2007) trata o diferente comportamento do PB, comparando-a ao processo encontrado em línguas crioulas, onde são feitas explicações "extralinguísticas" para responsabilizar o contato com outras línguas por esta "mudança particular" do PB. É sempre muito importante o papel da influência de outras línguas para a formação de uma língua, pois há sempre um conglomerado de variedades que podem influenciar umas às outras. Entretanto, ainda são insuficientes quaisquer explicações feitas a respeito das características intrínsecas do PB e do processo de mudança desta língua no que corresponde ao uso do artigo definido, portanto, não há evidências suficientes para assegurarmos ter havido influência direta das línguas que existiam no Brasil em séculos passados.

Dessa maneira, ao compararmos os resultados do PC com os do PB percebemos que o aumento no número de artigos se aplica em ambos, sobretudo nos dados do $\mathrm{PC}$, generalizando 
o uso do artigo em 100\% das ocorrências no português europeu atual. Com relação ao PC e ao PE atual, os dados apresentados evidenciam um panorama clássico do processo de mudança na língua. Neste caso, é bastante nítida a curva em "S" no aumento dos números de ocorrências, característica das mudanças linguísticas, e podemos atestar que o emprego do artigo em DPs possessivos passou a ser realizado categoricamente, evidenciando uma mudança sintática. E no que diz respeito aos padrões de aplicação do artigo no $\mathrm{PB}$, os dados evidenciam haver certo crescimento no número de ocorrências, mas que estas não seguiram o mesmo processo de desenvolvimento, o que revela um comportamento diferenciado ${ }^{11}$.

\section{Considerações Finais}

Verificamos nas línguas românicas, uma linearidade histórica em direção a uma obrigatoriedade contínua de utilização do artigo, que apresenta diferentes graus de desenvolvimento, nas línguas. No caso do francês, que é uma língua mais avançada nesse processo de gramaticalização, tais mudanças ainda não olevaram ao mais alto grau. Atestamos que "a escala universal de gramaticalização oferece indícios de probabilidades que, por determinadas razões, se repetem nas línguas do mundo, mas não correspondem necessariamente a um caminho predefinido", como atesta Kabatek (2007, p. 43). De acordo com o autor, o PB apresenta um comportamento particular do emprego do artigo, distanciando-se das demais línguas românicas. Além disso, o PB não se "encaixa" exatamente no quadro apontado por Greenberg (1978) no ciclo de gramaticalização, no que concerne ao continuum dos passos comuns aos processos de gramaticalização.

Dessa forma, atestamos as considerações de Kabatek (2007) a respeito do comportamento do $\mathrm{PB}$ em relação às línguas românicas. $\mathrm{O}$ PB apresenta tendências comparáveis a de outras línguas românicas pela eliminação do morfema de plural, a obrigatoriedade dos pronomes pessoais na função de sujeito e a substituição de pronomes enclíticos por proclíticos. Segundo Kabatek (2007, p. 42), a reestruturação do sistema do PB deve-se a motivos prosódicos, sendo de se esperar uma obrigatoriedade do artigo, assim como foi instanciado no PE. Entretanto, como verificamos, o PB segue um caminho próprio, distinto na tipologia das línguas românicas o que pode ser explicado devido às influências de outras

\footnotetext{
${ }^{11}$ Quais são essas possibilidades estruturais encontradas no PB serão objetos de pesquisas posteriores devido à grande gama de fatores envolvidos que ainda precisam ser bem delineados.
} 
línguas que circulavam no Brasil, mas uma análise minuciosa deve ser feita para assegurar tal hipótese.

\section{Referências bibliográficas}

CASTRO, A. Os Possessivos em Português Europeu e Português Brasileiro: Unidade e Diversidade. Actas do XVI Encontro Nacional da Associação Portuguesa de Linguística de Coimbra, Lisboa, APL, 599-613, 2000.

CASTRO, A. On Possessives in Portuguese. Ph.D. Dissertation, Universidade Nova de Lisboa - FCSH and Université Paris 8 -CLI, 2006.

CHOMSKY, N. A minimalist program for Linguistic Theory. In. K. Hale and S. J. Keyser eds. The view from Building 20: Essays in Linguistics in Honor of Sylvain Bromberger, 1-52. MIT Press, 1993.

CHOMSKY, N. The Minimalist Program. Cambridge, Mass., MIT Press, 1995.

CHOMSKY, N. Minimalist Inquiries. Cambridge, Mass: MIT Working Papers, 1998.

DEMSKYE, U. Prenominal Genitive Phrases as Definite Determiners. Unpublished manuscript, Universität Leipzig, 1995.

FLORIPI, S. O determinante em sintagmas nominais possessivos na história do português. Universidade Estadual de Campinas. Tese de doutorado, 2008.

FLORIPI, S. Do Português Clássico ao Português Europeu Moderno: o mapeamento do artigo. Letras\& Letras, vol.30, p 122-138, 2014. crossref http://dx.doi.org/10.14393/LL60v30n2a2014-7

GIORGI, A.; LONGOBARDI, G. The syntax of Noun Phrases. Cambridge: Cambridge University Press, 1991.

GREENBERG, J.H. How does a language acquire gender markers?. In: Greenberg, J. H. (Ed.). Universals of human language. World structure. Standford/Cal, p.47-82. vol.3, 1978.

HOPPER, P. E.; Traugott, E. C. Gramaticalization. Cambridge: Cambridge University, 1993.

KABATEK, J. Existe um ciclo de gramaticalização do artigo na România?. In: Para a história do português brasileiro”. Vol. V: Estudos sobre mudança linguística e história social. Ed. FALE/UFMG, Belo Horizonte, 2007.

KLARE, J. Lexicologia e fraseologia no português moderno. In: Revista de Filologia Românica, IV. Madrid: Editorial de la Universidad Complutense, 1986. Disponível em: http://www.google.com.br/url? sa $=t \& r c t=j \& q=\& e s r c=s \&$ source=web\&cd=1\&ved $=0$ CB4QFjA A\&url=http $\% 3 \mathrm{~A} \% 2 \mathrm{~F} \% 2 \mathrm{Frevistas} . u \mathrm{~cm} . \mathrm{es} \% 2 \mathrm{Findex} . \mathrm{php} \% 2 \mathrm{FRFRM} \% 2 \mathrm{Farticle} \% 2 \mathrm{Fdownload}$ \%2FRFRM8686110355A\%2F13195\&ei=3Du1U4aMG6rjsASm 4KQCg\&usg=AFQjCNEO 
DI I0QWsg9m 8p9cKtojDyOpig\&sig2=7rdgCpM92zJ1XfmZ5MWE3w . Acesso em 06 outubro 2014.

KURYŁOWICZ, J. The evolution of grammatical categories. Diogenes 51: 55-71. Reprint: KURYLOWICZ, J. 1975, Esquisses linguistique II. München: W: Fink, 1965.

LIGHTFOOT, D. Shifting Triggers and Diachronic Reanalysis. In: KEMENADE; A. v.; VINCENT, N. (orgs), Parameters of morphossyntatic change. Cambridge: Cambridge University Press, 1997.

MAgalhães, T. O Uso do Artigo Definido de Pronome Possessivo em Textos Portugueses do Século XVI a XIX. Qualificação em Sociolinguística, 2002.

OLSEN, S. Das Possessivum: Pronomen, Determinans oder Adjectiv? Linguísticsche Berichte 120:133-153, 1989.

RAMOS, J.; ALKIMIM, M. A. (organizadoras) Para a história do português brasileiro. Belo Horizonte: Faculdade de Letras da UFMG. 2007.

ROBERTS, I.; ROUSSOU, A. A Syntactic Change: A Minimalist Approach to Grammaticalization. Cambridge University Press, 2003. crossref http://dx.doi.org/10.1017/CBO9780511486326

SCHOORLEMMER, M. Possessors, Articles and Definiteness. In: Possessors, Predicates and Movement in The Determiner Phrase. ALEXIADOU, A.; WILDER, C. (eds), 56-86, John Benjamins Publishing Company, 1998. cross ref http://dx.doi.org/10.1075/la.22.04sch

SILVA, G. M. de O. Estudo da Regularidade na Variação dos Possessivos no Português do Rio de Janeiro. UFRJ. Tese de Doutorado, 1982.

SILVA, G. M. de O. Variação no Sistema de Possessivo de Terceira Pessoa. Tempo Brasileiro, (78/79:54-72), 1984.

SILVA, G. M. de O.; CALLOU, D. O uso do artigo definido diante de possessivo. In: DUARTE, I.; LEIRIA, I. (orgs.) Congresso Internacional sobre o Português, Colibri/APL, Lisboa, Vol.III. p. 115-125, 1996.

SIMÕES J. S.; KEWITZ, V. Cartas paulistas dos séculos XVIII e XIX: uma contribuição para os corpora do PHPB. São Paulo: Humanitas /FFLCH/USP, 2006.

SZABOLSCI, A. The Noun Phrase. KIEFER, N. F.; KISS, K. (eds) Syntax and Semantics 27. The Syntactic Structure of Hungarian. Academic Press, pp. 179-274, 1994. 